\title{
Preparation and Characterizations of Zeolite - Filled Natural Rubber/Poly(vinyl alcohol) Semi-IPN Membranes
}

\author{
J. Patthana ${ }^{1}$, C. Poonsawat ${ }^{2}$ \& S. Amnuaypanich ${ }^{3 *}$ \\ ${ }^{1,2 \& 3}$ Department of Chemistry, Faculty of Science, KhonKaen University, Khon Kaen 40002, Thailand
}

\begin{abstract}
Semi-interpenetrating polymer network (semi-IPN) of natural rubber (NR) and crosslinked poly(vinyl alcohol) (PVA) was composited with zeolite 4A to form a mixed matrix (MM) membrane. PVA was crosslinked with sulfosuccinic acid (SSA) in the immediate presence of NR and zeolite. FT-IR spectroscopy confirmed the crosslinking of PVA in the MM membrane. Swelling measurements were carried out in both water and absolute ethanol. The degrees of swelling in both water and ethanol increased with increasing PVA content in the membranes, however they were found to decline upon increasing zeolite content more than $10 \% \mathrm{w} / \mathrm{w}$. The mechanical properties of the MM membranes were investigated by tensile testing. It was observed that the modulus increased with increasing zeolite content in membranes but the elongation at break was found to decrease. The thermal degradation of the MM membranes was studies using thermal gravimetry (TG). The MM membranes showed higher thermal stability compared with NR/PVA membrane due to the incorporation of zeolite. The dispersion of zeolite particles in the MM membrane was observed by scanning electron microscopy (SEM) analysis which showed a well dispersing of zeolite particles in the semi-IPN matrix. The sorption selectivities of MM membranes were enhanced with zeolite content especially, at low water concentration of ethanol-water mixtures. However the sorption selectivities of MM membranes decreased when water content in the liquid mixtures increased.
\end{abstract}

Keywords: poly(vinyl alcohol), natural rubber, mixed matrix membrane, semi-IPN

\subsection{INTRODUCTION}

Pervaporation is a membrane process suitable for separating close-boiling point and azeotropic mixtures. In pervaporation process, liquid mixtures are fed under pressure to a membrane and the separated component passes through the membrane according to the difference in the permeability of liquid-mixture components through the membrane. The separated component will penetrate through the membrane and evaporate at the permeate side where vacuum is applied. Generally, pervaporation membranes can be classified as the hydrophobic and hydrophilic types. Hydrophilic membranes have the affinity for water or other polar compounds and normally

\footnotetext{
* Correspondence to: S. Amnuaypanich (email: asitti@kku.ac.th)
}

are used for the separation of mixtures containing water [1-2]. Hydrophilic membranes normally contain polar chemical groups for examples, poly (vinyl alcohol) (PVA), cellulose acetates and poly (vinyl amine). Hydrophobic membranes e.g. polyethylene or polydiymethyl siloxane, on the other hand, have little affinity for water or polar compounds and generally lack or contain a small proportion of charged or polar chemical groups. Hydrophobic membranes are employed for the separation of organic solvents from organic/ water solutions or organic/organic mixtures [3]. In this study, mixed matrix membranes were prepared by incorporating zeolite $4 \mathrm{~A}$ with a pore size of $4^{\circ} \mathrm{A}$ into dense membrane of NR/PVA semi-IPN. Because of the porous structure of zeolite, flux across the membrane can be enhanced while the separation efficiency is still 
maintained. Semi-interpenetrating polymer network (semi-IPN) membranes were prepared from a blend of crosslinked PVA and NR. PVA is hydrophilic polymer with a good film formation however it is highly swollen in water that cause a reduction in water separation efficiency. By introducing NR into PVA, the swelling of a membrane can be controlled and the water separation is more efficient.

\subsection{METHOD/THEORY}

\subsection{Materials}

Poly(vinyl alcohol) with 99\% hydrolyzed was purchased from Aldrich. Concentrated natural rubber latex (60\%w/w dry rubber content) was obtained from Thai Hua Rubber, Thailand. Sulfosuccinic acid (SSA) was purchased from Aldrich. Zeolite (4A) was provided by PQ Chemical, Thailand. Triton ${ }^{\circledR}$ X-405 for stabilization of NR was obtained from Sigma-Aldrich.

\subsection{Membrane Preparation}

NR/PVA membrane was prepared by dissolving PVA in deionized water at $90^{\circ} \mathrm{C}$, subsequently the NR latex stabilized with triton ${ }^{\circledR} \mathrm{X}-405$ was added to the PVA solution. SSA was added to crosslink PVA in the immediate presence of NR using $1 \mathrm{~mol}$ SSA per $8 \mathrm{~mol}$ of vinyl alcohol unit. The dispersion was constantly stirred at $70^{\circ} \mathrm{C}$ for 3 hours. The resultant dispersion was cast on a glass plate and the cast membranes were dried at $40^{\circ} \mathrm{C}$ for 48 hours. The preparation of the mixed matrix membrane was similar to the preparation of the NR/PVA membrane except that zeolite 4A was added into the PVA solution before adding NR latex.

\subsection{Membrane Characterizations}

The Fourier transform infrared (FT-IR) spectra of the membranes were obtained using PerkinElmer, spectrum one FT-IR spectrometer in the range of $4000-450 \mathrm{~cm}^{-1}$.

The morphologies of cross-sectional and the surface of the membranes were observed using
Scanning electron microscopy (SEM) (LEO 1450 VP). All specimens were coated with a conductive layer of sputtered gold.

The thermal stability of the membranes was examined using PerkinElmer pyris diamond TG/DTA from 30 to $600^{\circ} \mathrm{C}$ with heating rate of $10^{\circ} \mathrm{C} / \mathrm{min}$ under nitrogen atmosphere.

The mechanical properties of the membranes were obtained using Universal testing machine . (Lloyd Instruments UK model LR $50 \mathrm{~K}$ ) on dumbbell shaped samples following ASTM D412-C. The crosshead speed was $20 \mathrm{~mm} / \mathrm{min}$.

The swelling of the membranes was determined gravimetrically. Dry membrane $W_{d}$ was immersed in the water or ethanol for 48 hours. Then the membrane was taken out, wiped with filter paper and immediately weighed $W_{s}$. The degree of swelling (DS) was calculated by:

$$
D S(\%)=\frac{W_{s}-W_{d}}{W_{d}} \times 100
$$

The sorption behavior of the membrane was examined by the following procedure. The dry membrane was immersed in ethanol-water solutions for 48 hours. Then the sorbed membrane was placed in the flask which is connected to a cool trap and a vacuum pump. The flask was heat to $100^{\circ} \mathrm{C}$. Thus the sorbed liquid was removed from the membrane and the vapor was condensed in the solvent trap cooled with liquid nitrogen. The condensed liquid was analyzed by refractive index detector (waters RI 2414) and the sorption selectivity $\left(\alpha_{s}\right)$ was calculated by:

$$
\alpha_{s}=\frac{C_{\mathrm{H}_{2} \mathrm{O}} / C_{E t \mathrm{OH}}}{X_{\mathrm{H}_{2} \mathrm{O}} / X_{E t O H}}
$$

Where $X$ and $C$ are the weight fractions of species in the feed and sorbed membrane respectively.

\subsection{RESULTS AND DISCUSSION}

\subsection{FT-IR Spectra}

The FT-IR spectra of PVA, crosslinked PVA, NR/ PVA $(20 \% \mathrm{w} / \mathrm{w}$ PVA) and NR were shown in 
Figure 1. PVA spectrum showed absorption bands around $3300 \mathrm{~cm}^{-1}$ and $1430 \mathrm{~cm}^{-1}$ corresponding to $\mathrm{OH}$ of a primary alcohol [4]. For crosslinked PVA, the absorption band of ester can be observed at $1730-1735 \mathrm{~cm}^{-1}$. The absorptions bands at 1252,1087 and $1035 \mathrm{~cm}^{-1}$ attributed to sulfonic acid groups of crosslink agent SSA [5]. The band at $3000-3600 \mathrm{~cm}^{-1}$ of the hydroxyl groups shows a decrease in its intensity in comparison to that of PVA. This suggests that some of hydroxyl groups along PVA chains reacted with carboxyl groups of SSA in the crosslinking reaction. The characteristic peaks of NR can be observed at 831 and $1660 \mathrm{~cm}^{-1}$ corresponding to the stretching and bending of the $\mathrm{C}=\mathrm{C}$ of isoprene unit. For NR/ PVA membrane all characteristic peaks of both crosslinked PVA and NR were observed indicating that PVA was crosslinked in the presence of NR forming a semi-IPN structure.

\subsection{SEM}

Figure 2 shows the SEM micrographs of crosssection and surface of the MM membranes. The zeolites were well dispersed within the semi-IPN matrix. However some of zeolite aggregates can be observed for $40 \%$ w/w zeolite [6].

\subsection{Thermal Degradation}

Figure 3 shows the TG curves of the NR/PVA membranes and the MM membranes. The weight loss of NR/PVA membranes can be divided into 2 stages. The first weight loss around $220-300^{\circ} \mathrm{C}$ is due to a weight loss of the sulfonic acid group and a breakage of crosslink sites [5]. The second weight loss around $350-470^{\circ} \mathrm{C}$. was due to the decomposition of both NR $\left(350^{\circ} \mathrm{C}\right)$ [7] and PVA $\left(300-470^{\circ} \mathrm{C}\right)$ [8]. The weight loss at temperature lower than $150^{\circ} \mathrm{C}$ corresponds to a loss of adsorbed-water. For the MM membranes, the weight loss profile was similar to that of NR/PVA except that there appeared the residue after $600^{\circ} \mathrm{C}$ which was mainly zeolite.

\subsection{Mechanical Property}

Figure 4 shows the plot of stress versus strain for the tensile testing of the membranes also, the modulus and elongations at break obtained from

(a)

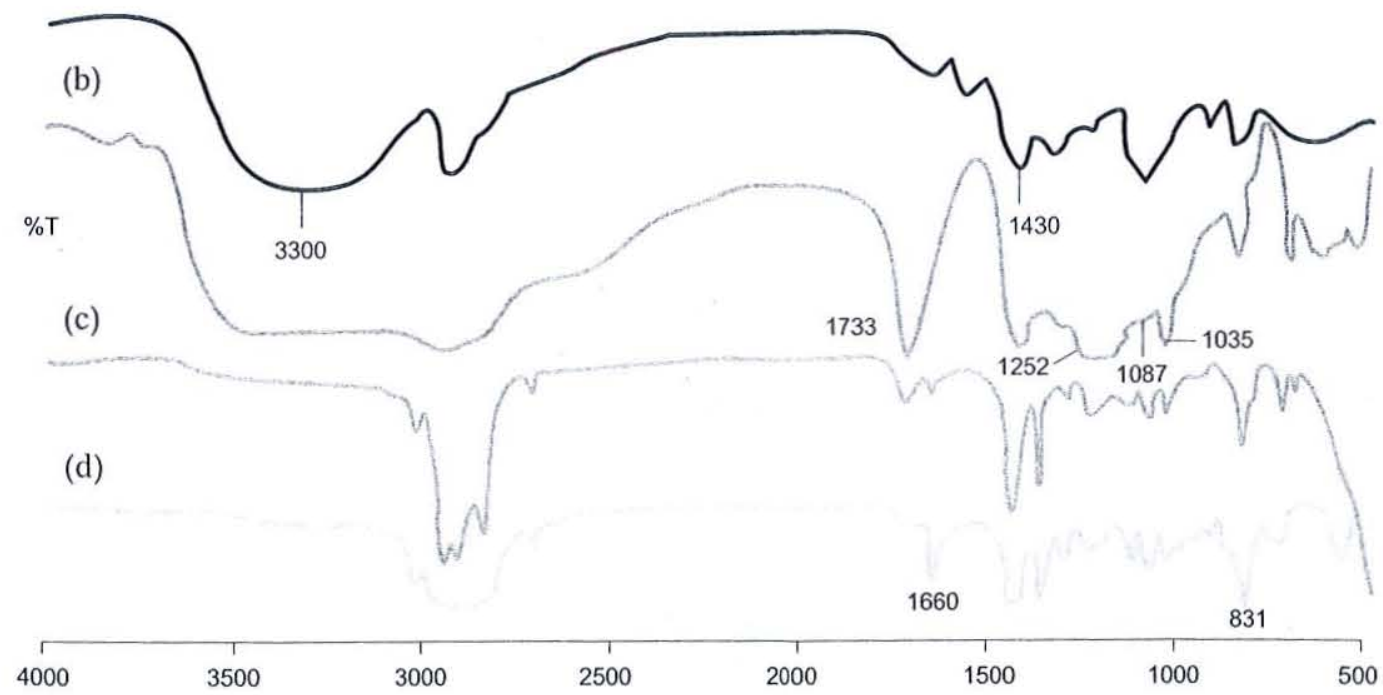

Figure 1 FT-IR spectra of (a) PVA (b) crosslinked PVA (c) NR/PVA and (d) NR 

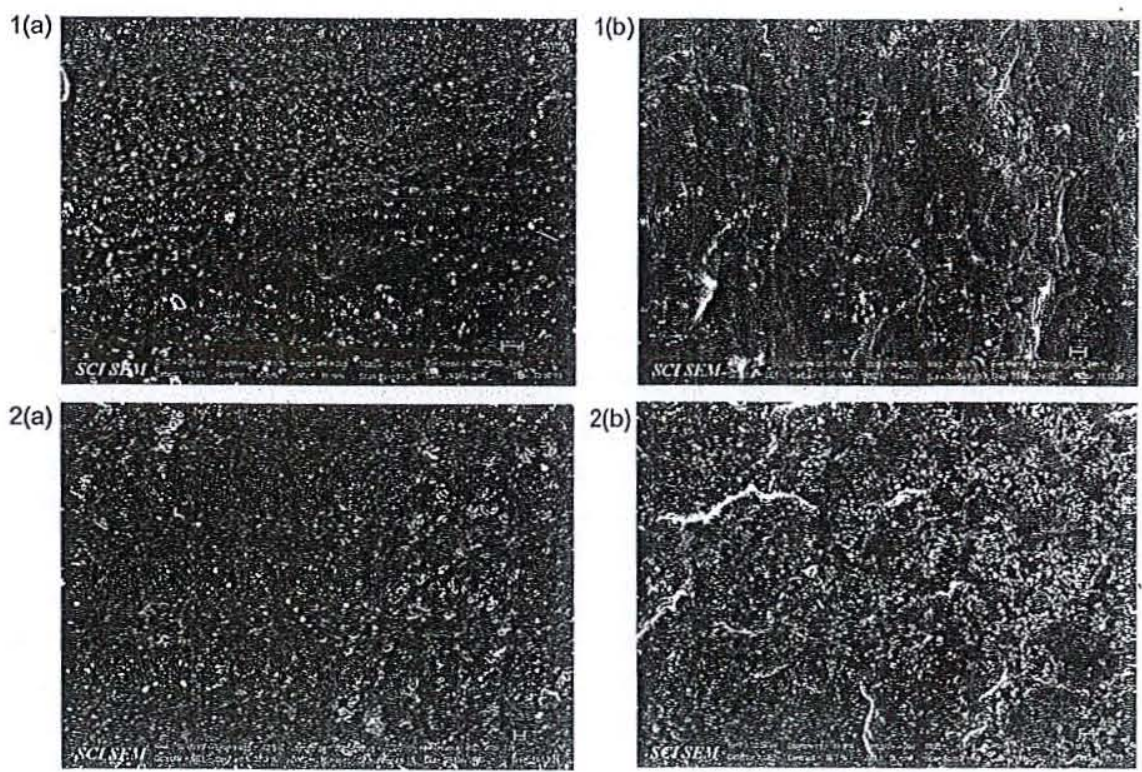

Figure 2 SEM micrographs of MM membranes: (1) $10 \%$ w/w zeolite (2) $40 \%$ w/w zeolite; (a) surface and (b) cross-section

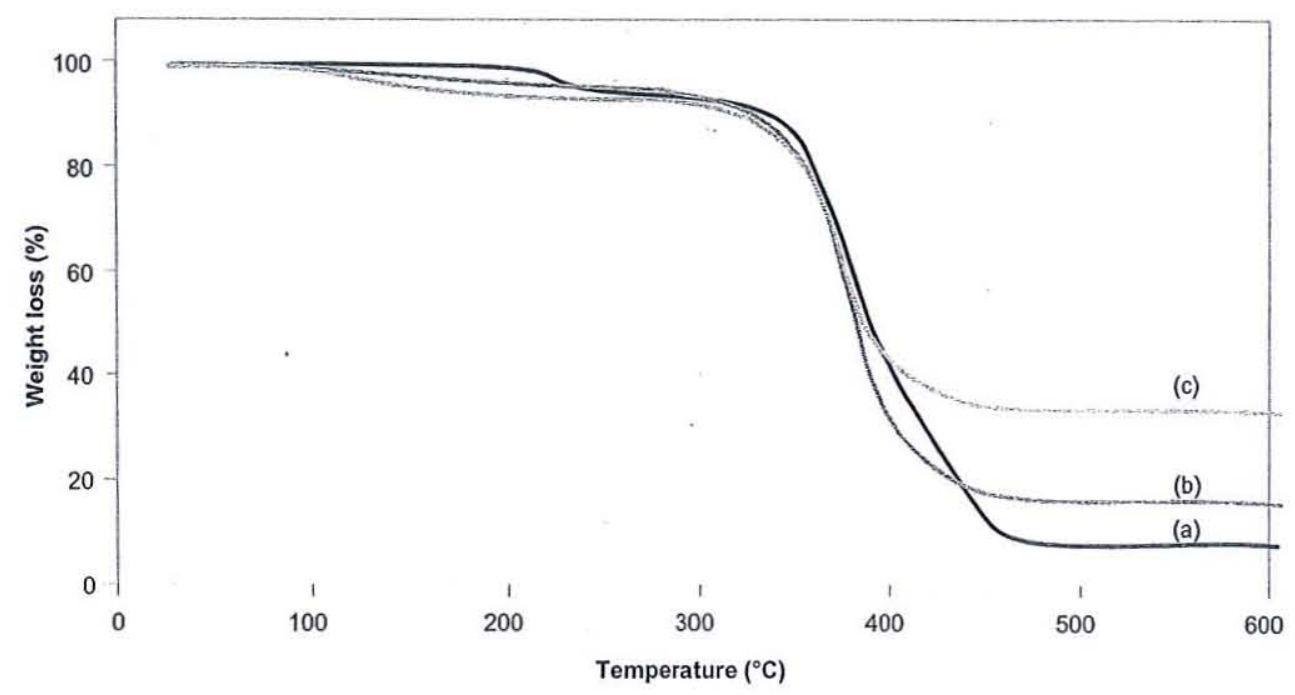

Figure 3 TG curves of the membranes: (a) NR/PVA (b) NR/PVA filled with $20 \%$ w/w zeolite and (c) NR/PVA filled with $40 \% \mathrm{w} / \mathrm{w}$ zeolite

the plot were tabulated in Table 1. Evidently, NR/PVA membrane possessed higher modulus than that of NR however; the elongation at break was lower. This is due to the more crystallinity of PVA. Similarly, incorporating zeolite with NR/PVA membrane would enhance the modulus but reduce the elongation indicating the property of composite polymers. Nonetheless, for 40 $\% \mathrm{w} / \mathrm{w}$ zeolite content, the MM membrane was ruptured at lower strain than the MM membrane at $20 \% \mathrm{w} / \mathrm{w}$ zeolite which may be arise from the zeolite aggregation at high zeolite loading. 


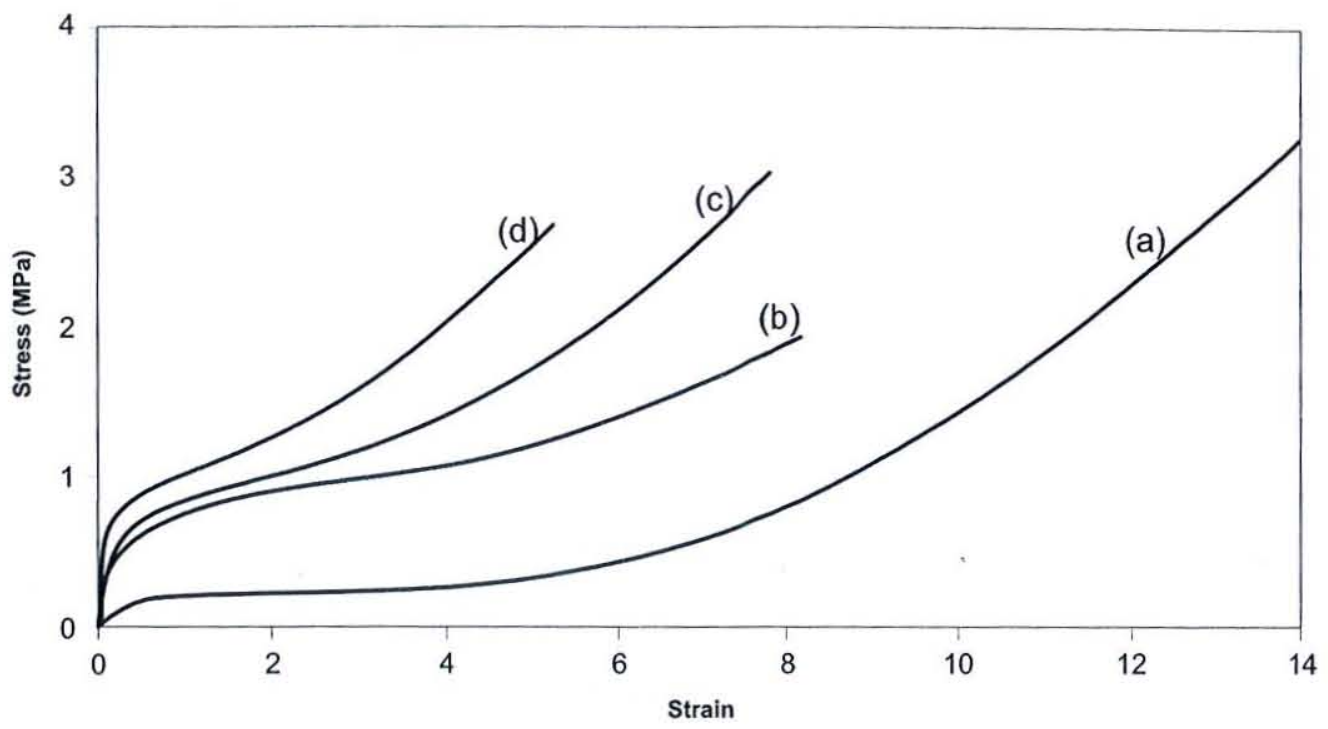

Figure 4 Stress-strain curves of the membranes: (a) NR (b) NR/PVA without zeolite (c) NR/PVA filled with $20 \%$ w/w zeolite (d) NR/PVA filled with $40 \%$ w/w zeolite

Table 1 Mechanical property of the membranes

\begin{tabular}{lccr}
\hline \multicolumn{1}{c}{ Membrane } & $\begin{array}{c}\text { Initial's } \\
\text { modulus } \\
\mathbf{( M P a )}\end{array}$ & $\begin{array}{c}\text { Tensile strength } \\
\text { at break } \\
\mathbf{( M P a )}\end{array}$ & $\begin{array}{c}\text { Elongation } \\
\text { at break } \\
\mathbf{( \% )}\end{array}$ \\
\hline NR & 0.29 & 3.52 & 1352.30 \\
NR/PVA (10 \%w/w PVA) & 0.61 & 1.48 & 664.16 \\
NR/PVA-Z20 (10 \%w/w PVA, 20 \%w/w zeolite) & 0.84 & 2.90 & 710.03 \\
NR/PVA-Z40(10 \%w/w PVA, 40 \%w/w zeolite) & 1.42 & 2.74 & 469.94 \\
\hline
\end{tabular}

\subsection{Degree of Swelling}

Figure 5 shows degree of swelling of MM membranes in water and ethanol. It can be seen that the degree of swelling both in water and ethanol increased with increasing PVA content by which the water swelling degree increased more significantly than those of swelling in ethanol due to the hydrophilicity of PVA. The MM membrane at $10 \% \mathrm{w} / \mathrm{w}$ zeolite loading was swollen more than NR/PVA because the water molecules can access into the pore structure of zeolite. However, at high zeolite loading in MM membranes, the hydrophilicity of membrane decreased due to a decreasing PVA resulting in the decline of swelling degree.

\subsection{Water Sorption Sselectivity $\left(\alpha_{s}\right)$}

Figure 6 shows the $\alpha_{s}$ of MM membranes in ethanol-water mixtures. It can be seen that sorption selectivities of MM membranes increased considerably with increasing zeolite content for $5 \% \mathrm{v} / \mathrm{v}$ water in ethanol-water mixtures. For higher water content, the sorption selectivities of MM membranes remained constant because the molecular sieving effect of zeolite which allows only water molecules to enter the pores excluding larger ethanol molecules. At high water content, the swelling membrane increases which causes the free volume to expand allowing more ethanol to penetrate the membrane structure more easily and counteract the molecular sieving effect. 


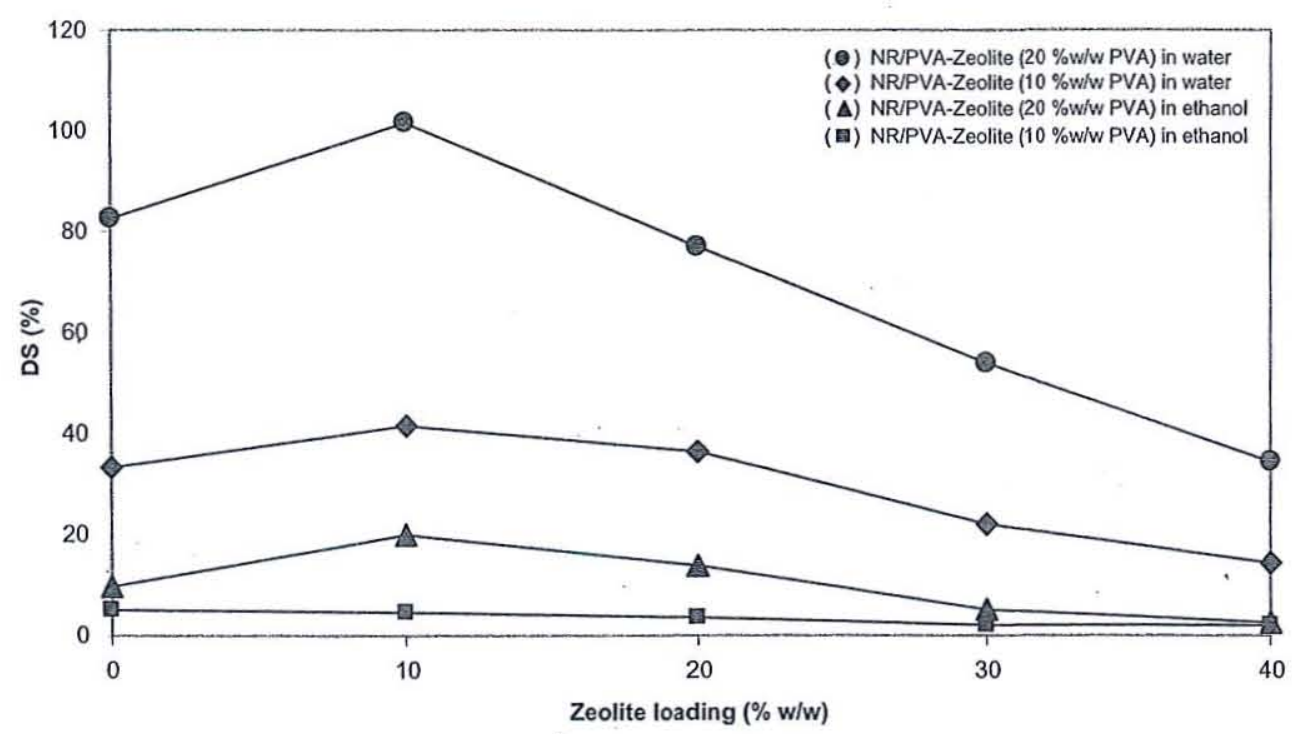

Figure 5 Degree of swelling of MM membranes in water and ethanol

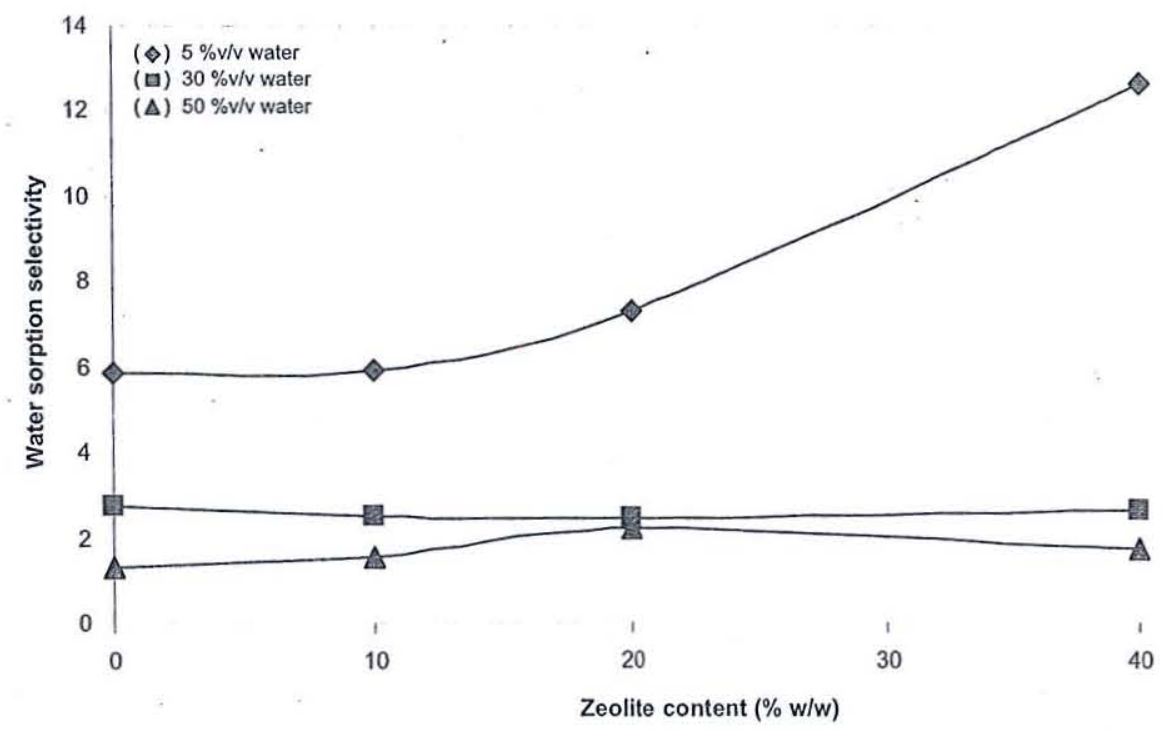

Figure 6 The sorption selectivity of MM membranes (10\%w/w PVA) in ethanol-water mixture

\subsection{CONCLUSION}

The mixed matrix (MM) membranes were prepared from blend of natural rubber and crosslinked PVA incorporated with zeolite $4 \mathrm{~A}$. The degree of swelling in water was found to increase with increasing PVA content in the membranes however adding the zeolite more than
$10 \% \mathrm{w} / \mathrm{w}$ leaded to the decrease of membrane swelling. The MM membranes showed higher thermal stability than NR and NR/PVA membrane due to the presence of zeolite. Because of incorporating zeolite, the mechanical property of the MM membranes shows higher modulus but the elongation at break was lower compared to NR/PVA membrane. The sorption selectivities of 
MM membranes increased with increasing zeolite content at low water concentration of ethanolwater mixtures but at high water content the sorption selectivities of MM membranes decreased because of the swelling effect.

\section{ACKNOWLEDGMENTS}

The authors would like to thank Integrated Nanotechnology Research Center, Khon Kaen University (NANOKKU) and Thailand Research Fund (TRF) under Small Project Rubber for the financial supports.

\section{REFERENCES}

[1] Buyanov, A.L., L.G. Revel'skaya, Yu.P. Kuznetzov and A.S Shestakova. 1998. Cellulose-Poly(acrylamide or acrylic acid) Interpenetrating Polymer Network Membranes for the Pervaporation of WaterEthanol Mixture. J. Appl. Polym. Sci. 69: 761-769.

[2] Ruckentein, E., and L. Liang. 1996. Poly (acrylic acid)-Poly(vinyl alcohol) Semi- and Interpenetrating Polymer Network Pervaporation Membranes. J. Appl. Polym. Sci. 62: 973-987.

[3] Wojciech C., O.-G. Barbara, J. Kozakiewicz, K. Wojciech, and A. Warszawski. 2004.
Siloxane-urethane Membranes for Removal of Volatile Organic Solvents by Pervaporation. Desalination. 163: 207-214.

[4] Liang, L., and E. Ruckenstein. 1995. Polyvinyl Alcohol-polyacrylamide Interpenetrating Polymer Network Membranes and their Pervaporation Characteristics for Ethanol-water Mixtures. J. Memb. Sci. 106: 167-182.

[5] Rhima, J.-W., H.B. Park, C.-S. Lee, J.-H. Jun, D.S. Kim, and Y.M. Lee. 2004. Crosslinked poly(vinyl alcohol) Membranes Containing Sulfonic Acid Group: Proton and Methanol Transport through Membranes. J. Memb. Sci. 238: 143-151.

[6] Sun, H., L. Lu, X. Chen, and Z. Jiang. 2008. Surface-modified Zeolite-filled Chitosan Membranes for Pervaporation Dehydration of Ethanol. Applied Surface Science. 254: 5367-5374.

[7] Fernandez-Berridi, M.J., N. Gonzalez, A. Mugica, and C. Bernicot. 2006. PyrolysisFTIR and TGA Techniques as Tools in the Characterization of Blends of Natural Rubber and SBR. Thermochimica Actá. 444: 65-70.

[8] Peng, Z., and L.X. Kong. 2007. A Thermal Degradation Mechanism of Polyvinyl Alcohol/silica Nanocomposites. Polymer Degradation and Stability. 92: 1061-1071. 